\title{
Design of a Talent Recruitment \& Job-Hunting System Based on Smartphone
}

\author{
Suolan Liu, Lizhi Kong*, R Song \\ Changzhou University, Jiangsu, China, 213164 \\ lan-liu@163.com
}

Keywords: Recruitment, Job-hunting, Enterprises, Seekers, System

\begin{abstract}
With the development of enterprises as well as the continuous expansion of higher education, the tradition recruitment fairs cannot meet the needs of supply and demand. In this paper, we develop a system based on mobile phone, which can provide a fast and effective way for both enterprises and job seekers. The system offers the function of quickly posting talent requirements, and provides convenient way for job seekers to filter suitable job positions. Make the talent recruitment and job-hunting become easy at the primary stage.
\end{abstract}

\section{Introduction}

With the development of computer science and technology, Internet has been a part of our daily life, which affects and changes our living models. Internet offers us more than just a source of information, but also a platform to communicate with others. Every year, there are many college students need to hunt jobs, which makes the original employment pressure becomes more serious. As we know, talent is the key to an enterprise's development. How to be able to get talent with the required ability is a problem concerned by enterprise's human resources department (HR). At the same time, cannot apply for an interesting job and exert his cleverness and intelligence is the seeker's trouble. For a long time, the traditional job fairs are the main mean of communication between employers and seekers. But, it is known that this traditional way has many shortcomings, such as:(1) Job fairs are held regularly and constrained by time. The job fairs are usually done in a limited few days by offering face-to-face communication opportunities for employers and seekers. Even though some companies advertise themselves by posters or other ways ahead of time, there are still many seekers miss the fairs. There are also some seekers have to give up some important things to attend the fairs. (2) It is difficult to manage for numerous persons. The fair site is usually very crowed for so many people attending the job fairs, which makes the fair be difficult to manage. More importantly, there is potential security threat. Therefore, we can make use of Internet to improve the tradition job fairs. Nowadays, smartphone apps have been widely used in our daily life, so developing a mobile web platform and offering jobs information would have great help for both job seekers and employers by saving much time, money and energy. This system will provide a two-way communication and selection platform for employers and job seekers. Users can freely communicate on the website. Enterprise posts the job information, and then seeker can read and select the job position after signing up. If the seeker is interested to a job, he can send his individual information on line.

\section{Feasibility Analysis and Requirements Analysis}

The purpose of feasibility analysis and requirements analysis is to judge and determine whether the problems can be solved in a possible shortest time with minimal cost. So, it is necessary to analyze the system and consider the pros and cons of our solutions.

Feasibility Analysis. The system should meet the needs of employers and seekers by comprehensively considering the rapid increasing and development of talents and enterprises. It should make the primary selection of employees and jobs easy. Therefore, the system should be able to provide these functions: (1) Enterprises and seekers can view the recruitment information at any time. (2) Provide recently accurate job recruitment information. (3) The interfaces should be friendly 
and easily used. (4) Flexible in query. (5) The permission is clear distributed. (6) High security and ease of maintenance.

Requirements Analysis. The main purpose of developing this system is to provide convenient and quick job information for enterprises and seekers communication and selection. So, the users mainly include these kinds: seekers with looking for appropriate job positions and enterprises with talent recruitment needs. Based on these, the functions of this system can be analyzed from the next two aspects: (1) Analysis from the perspective of information requirements. By registration, the system can collect the information from individual seeker and enterprise. By job information management, the system can count various types of job information and realize the follow-up management. (2) Analysis from the perspective of users. It requires job seekers to register their individual information and records the resume delivery information. It should review the enterprise's legitimacy before post recruitment information. Web administrator can manage all individual users and enterprise users.

Based on the feasibility analysis and requirements analysis, we can design the system E-R chart as shown in Figure 1.

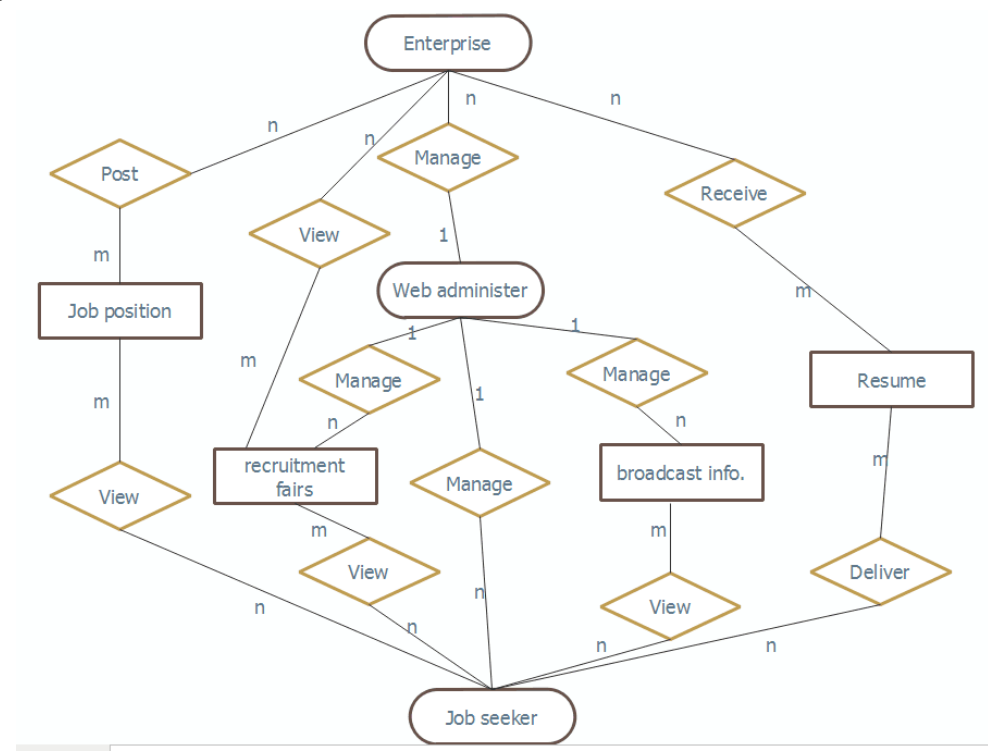

Figure 1 System E-R Chart

\section{Overall design of this system}

This system uses the typical B/S architecture. Compared with the traditional C/S architecture, it saves a lot of cost in system deployment, implementation and maintenance. The system provides different interfaces for different kinds of users. Enterprises can use the 'Recruitment' function to post talent recruitment information. At the same time, job seekers can use the function of 'seeking' to search job positions. Through this interactive communication, meet the needs of both parties. So, for this system we mainly design the following functional modules shown in Figure 2.

Enterprise's Talent Recruitment Module. If an enterprise needs talents, it firstly needs to register as an authorized user. After legality verification, it can post job requirements. The enterprise needs to manage its own information, so the recruitment management function is essential. To quickly filter the seekers, it should have the function of 'talent searching' for query.

Job Seeking Module. Once signing up, the seeker can use the function of 'job searching' to select the interested job positions. Of course, different searching factors can be set for query. Furthermore, he can deliver electronic resume to suitable position and view the reply on time.

Information Broadcast Module. In the module, the web administor can post some hot topic news, recruitment fairs information, policies and experience and so on.

Background Management Module. In this module, web administor can manage all registered users. It can add, modify or delete the broadcasted information. 


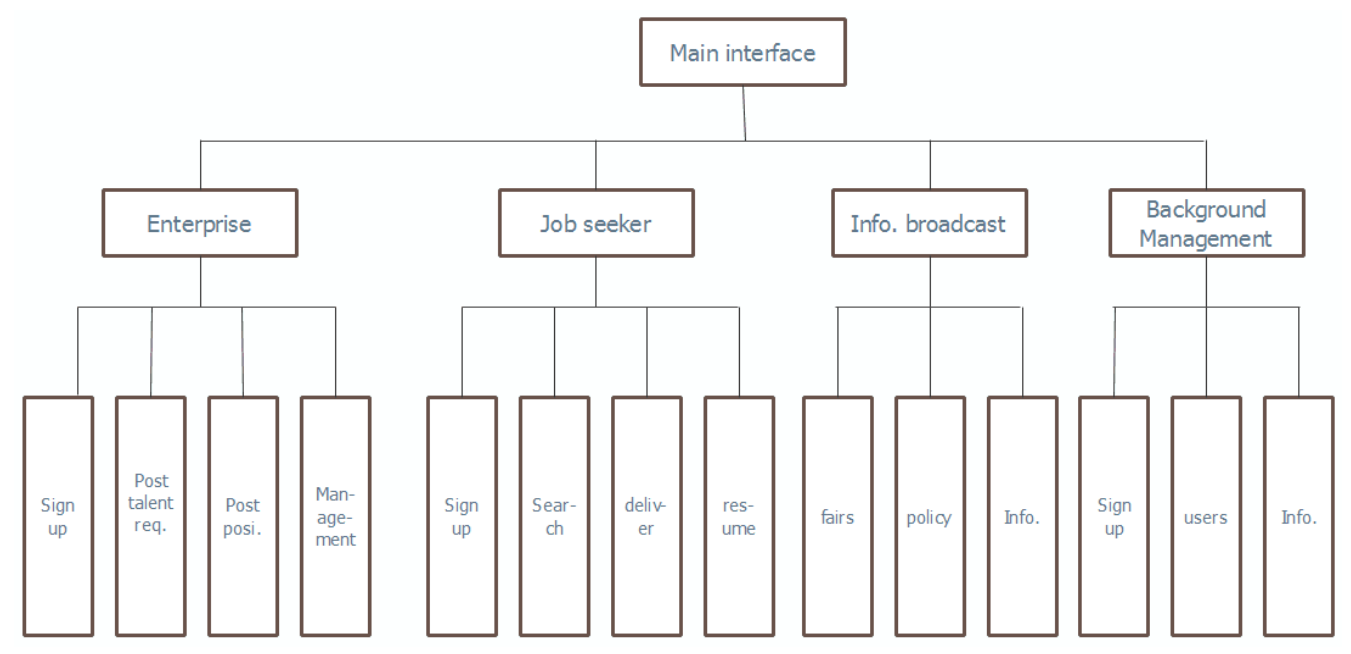

Figure 2 Functional modules

\section{Implementation of the Talent Recruitment \& Job-hunting System}

Combining the needs of enterprises and job seekers, we develop a valuable system, which can be freely used in Android and IOS platforms. The system is based on JavaScript, html5 and CSS3. Some typical application interfaces are shown in Figure 3 to Figure 5. Figure 3 shows the system's main interface. It displays the latest talent recruitment information. Of course, by operating the 'job type' menu, the user can easily filter the cared jobs. Figure 4 is enterprise's register page. To be an authorized user and post recruitment information, the enterprise should offer some detail information for web administor verifying. A job position's detail information is shown in Figure.5. It lists the seeker's cared and enterprise's requirements as much as possible.

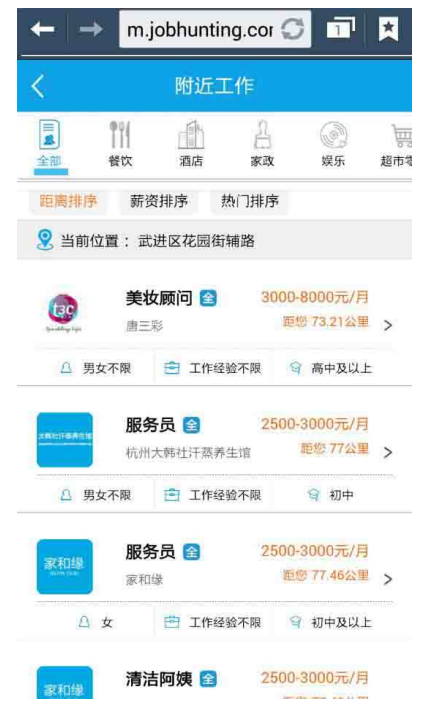

Figure 3 Main interface Figure 4 Enterprise register interface

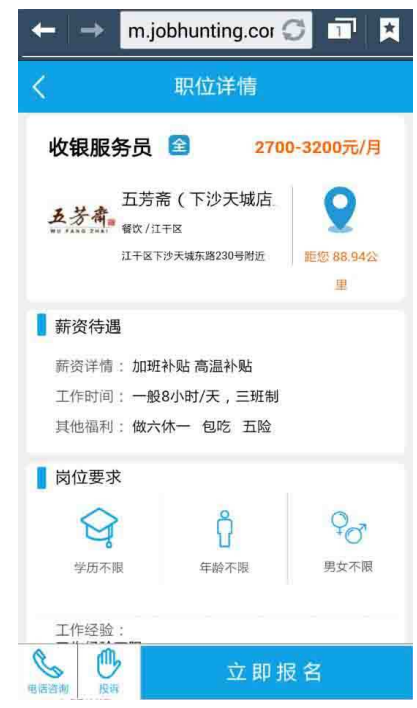

Figure 5 Position's detail information

\section{Conclusion}

A talent recruitment and job-hunting system based on smartphone is developed in this paper. This system uses html5+CSS3 architecture, which lets users feel more comfortably. This design can provide good extendibility for adding other required functions. Test results show that this system has these advantages such as data stable, user-friendly interface and easy operation. At present, the system is still in testing phase. We expect it to be put into practical use in the near future. 


\section{Acknowledgements}

This work is supported by the project of Changzhou University (No.2015XSJ11) and project of Changzhou science and education town (No.CDGZ2016002).

\section{References}

[1] J Zhang. The design and implementation of recruitment system based on bootstrap and SSH [J]. Computer guide, 2013, 15-18.

[2] Y Huang. University research management policy and system in our country [J]. Journal of education and economy, 2016, 15(10).

[3] J Qiang. Design of android-based job information platform[J], 2016,29(12) .

[4] S Liu, LKong. Research and Design of a Commodities Trading System[J], Advances in Computer Science Research,2017,1080-1083.

[5] J Wang, Q Zhao. Design and implementation of employment and recruitment websites system based on JSP [J]. Value engineering, 2016,35(35).

[6] J Hang. The Design and Implementation of Job Search and Recruitment System[J]. Journal of Hubei University of Education, 2014, 31(2).

[7] Q He. Design and application of employment system based on Web[J]. Journal of Pingdingsan university, 2005, 20(5).

[8] H Lu. Design and implementation of network recruitment system[J]. China Computer \& Communication, 2016, (14).

[9] Y Xu. Method of JQuery Mobile 1.2 in mobile Web development[J],Information Technology, 2013, (8).

[10] Q Wu. Research on Core Technology of HTML5 Web Development Standard[J]. Journal of Xuchang University, 2011, 30(5).

[11] H Qian. Research of Web Mobile Pages Development Technology Based on HTML5[J]. Computer and Information Technology, 2013, 21(1).

[12] Z Zhang. To Investigate the HTML5 and CSS3.0 New Features and Advantages in the Design of Webpage[J]. Journal of wuxian hulian keji, 2015, (8)

[13] Z Liu. A recruitment system's design based on JAVA[J]. Software guide, 2014, 11.

[14] A Zhao. Research and implementation of M-Learning platform based on HTML5 and NET. Journal of Henan Institute of Science and Technology, 2013, 41(4).

[15] S Qu. The Theme Page Implementation on Weather Forecast Website Based on HTML5+CSS3[J]. Journal of Anhui Vocational College of Electronics \& Information Technology, 2017, 16(1). 